\title{
Termination of second and early third trimester pregnancy: comparison of 3 methods
}

Sir,

I am writing with regard to an article written by Bani-Irshaid et al. in the Eastern Mediterranean Health Journal in 2006 [1]. It is an enlightening article on the use of Foley catheters for the termination of pregnancy. The historical discussion of devices related to the research unfortunately contains inaccuracies.

The authors attribute the invention of the Foley catheter to Albert Krause in 1833. This is not correct. The Foley catheter is named after Frederic Foley who invented the inflatable latex rubber catheter with integrated balloon 100 years later than Krause [2]. While Embrey and Mollison did show how to use the Foley catheter for induction of labour in the 1960s [3] the first instantiations of inflatable Foley-like devices for induction were introduced by Antoine Mattei in 1855 [4] and Horatio Storer in 1859 [5]. Many also consider the work of Robert Barnes in improving similar inflatable rubber dilators in the 1860s [6] as key to later developments by Embrey and Mollison and others.

It is important to ensure that the historical record is accurate. However, none of this discussion on historical events should detract from the scientific results of Bani-Irshaid et al.'s work. Their conclusions about the safe and effective use of the Foley are in agreement with results from many other practitioners and researchers.

\section{References}

1. Bani-Irshaid I et al. Termination of second and early third trin mester pregnancy: comparison of 3 methods. Eastern Mediterranean Health Journal, 2006, 12(5):605-609.

2. Foley FEB. A hemostatic bag catheter-a one piece latex rubber structure for control of bleeding and constant drainage following prostatic resection. Journal of Urology, 1937, 38(1):134-139.

3. Embrey MP, Mollison BG. The unfavourable cervix and induce tion of labour using a cervical balloon. International Journal of Obstetrics and Gynaecology, 1967, 74(1):44-48.
4. Mattei A. Essai sur l'accouchement physiologique. Paris, France, Victor Masson, 1855.

5. Storer HR. The uterine dilator. American Journal of the Medical Sciences, 1859, 38:107-113.

6. Barnes R. On the indications and operations for the induction of premature labour and for the acceleration of labour. Obstetrical Transactions, 1861, 3:107-141.

\section{J.A. Smith}

Department of Electrical and Computer Engineering, Ryerson University, Toronto, Canada (jasmith@ee.ryerson.ca). 